\title{
Implicações de distintas compreensões de cultura visual
}

Raimundo Martins

\section{Resumo}

Este artigo discute as circunstâncias através das quais o pós-modernismo favorece e incentiva a reprodução de atitudes, o consumo de objetos e artefatos representados por ou associados a imagens, analisando como essa hibridização confunde os limites impostos pelas estruturas de informação e conhecimento baseadas em cânones acadêmicos. Examina abordagens de pesquisa que incorporam as mídias e artefatos visuais contemporâneos ao corpus de conhecimento da arte/educação apontando alternativas para abordar, investigar e compreender o modo como os indivíduos concebem e constroem o imaginário imagético que essas mídias e artefatos animam.

Palavras-chave: Imagem, Arte contemporânea, Pesquisa, Cultura Visual.

\begin{abstract}
This article discusses circumstances through which postmodernism favors and incentivizes the reproduction of attitudes, the consume of objects and artifacts represented or associated to images, analyzing how this hybridization confuses the limits imposed by information and knowledge structures based in academic canons. It examines research approaches that incorporate contemporary media and visual artifacts to the corpus of knowledge of art education pointing to alternatives to approach, investigate and understand the way individuals conceive and construct the imagetic imaginary these media and artifacts animate.
\end{abstract}

Keywords: Image, Contemporary art, Research, Visual Culture.

\section{Circunstanciando atitudes e contextos...}

Elasticidade, transitoriedade e ambivalência, características da pós-modernidade, tem contribuído para tornar os significados cada vez mais fluidos e contextuais ampliando o espectro de interpretações que podem derivar de qualquer trabalho, imagem ou objeto a partir de diferentes perspectivas, sejam elas de artistas, docentes, intelectuais ou de um público em geral que compõe esse grupo impessoal que chamamos de audiência, receptor etc. Como condição cultural, o pósmodernismo favorece e incentiva a reprodução de atitudes, o consumo de objetos, jogos e artefatos representados por ou associados a imagens. Essa pulsão para consumir não está apenas vinculada ao produto em si, mas, à sua representação estética, destacando sua dimensão expressiva. Pode-se dizer que esses artefatos não valem pelo preço, mas, pelo que representam emocionalmente. Com 
frequência, esses elementos são uma fusão de formas visuais e estratégias conceituais.

Assim, imagem e visão constituem condições vitais para o modo como nos relacionamos, nos comunicamos, representamos e damos sentido às coisas que nos rodeiam. Esta abordagem partilhada por pesquisadores e teóricos (WALKER e CHAPLIN, 1997; MIRZOEFF, 1999; MITCHELL, 2002; PINNEY, 2006), embora não seja consensual, tem sua principal referência na virada cultural dos anos 80 do século passado (HALL, 1997) e se distingue por sua ênfase no significado como uma maneira de observar, estudar e compreender ações, fenômenos e práticas coletivas que envolvem a imagem. Esta noção de cultura visual, cujas raízes germinaram no campo dos Estudos Culturais, ganhou espaço nas Ciências Sociais revelando uma índole antropológica que destaca os "processos sociais" em detrimento de uma análise específica que privilegie os "artefatos visuais". Esta abordagem põe em perspectiva o momento e as condições sociais, culturais e históricas que fermentam determinadas produções imagéticas, articulando e pondo em evidência questões relacionadas "a ética, política, estética e epistemologia do ver e do ser visto" (MITCHELL, 2002, p. 166).

A teoria crítica e, especialmente, o construtivismo cultural, explicitam a compreensão de que as imagens, como fenômenos visuais cuja principal característica está vinculada ao modo como nos relacionamos com o outro, com o mundo e conosco mesmos, constituem um processo de aprendizagem social e culturalmente construído. Esta perspectiva responde a demandas contemporâneas específicas, gerando trânsitos e deslocamentos que se articulam como pedagogias da cultura visual, baseados no princípio de que "nenhum tipo de fenômeno visual [deve ser] excluído, valorizado ou previamente classificado segundo conceitos normativos como boa qualidade, bom gosto, boa forma etc." (ILLERIS e ARVEDSEN, 2012, p. 287). As implicações dessa perspectiva apontam para o fato de que as culturas das imagens não tem como ser estudadas e abordadas pedagogicamente por uma única narrativa dominante. Isso quer dizer que conhecimento, sensibilidade e, sobretudo, experiência estética, são passíveis de ser vividos e experimentados em relação com outros tipos de imagens e fenômenos visuais e não apenas com aqueles tradicionalmente caracterizados como belas artes.

A ideia de trânsitos e deslocamentos, sejam eles conceituais, perceptivos e pedagógicos, possibilitam aproximação com outras culturas das imagens - imagens 
de informação, publicidade, ficção, entretenimento, fílmicas etc. - levando-nos a compreender que esses artefatos visuais também geram aprendizagens que ensejam abordagens críticas e analíticas. O que está em jogo, de fato, não é necessariamente o modo como os indivíduos veem o mundo, mas, como eles veem imagens fixas e em movimento e, sobretudo, como veem a infinidade de artefatos visuais que nos rodeiam e estimulam cotidianamente (WALKER e CHAPLIN, 1997).

A cultura visual ainda não é uma disciplina institucionalizada e pode-se dizer que parte significativa dessa resistência está vinculada ao seu caráter transdisciplinar, talvez, quase nômade, embasado em estudos e pesquisas "provenientes de ramos científicos, artísticos e humanísticos que buscam, grosso modo, algo comum: apreender a imagem, o olhar e a visualidade enquanto construções humanas, social e historicamente situadas" (CAMPOS, 2013, p. 51).

Esse diversificado espectro de abordagens está ancorado em pontos de convergência (ROSE, 2011) que tem como foco diferentes "modos de olhar socialmente e culturalmente contextualizados; uma ênfase na centralidade das imagens visuais nas formações culturais mais amplas" e, ainda, "a importância crescente da audiência enquanto agente produtor de significado" (CAMPOS, 2013, p. 52).

Nesse sentido, é possível dizer que fenômenos e artefatos visuais são híbridos visual e conceitualmente. Essa hibridização é, também, uma marca de muitas produções artísticas da cultura pós-moderna, fugindo dos limites impostos pelas estruturas de informação e conhecimento baseadas em disciplinas e cânones acadêmicos. Como exemplo dessa hibridização, observem a imagem que segue: (Figura 1) 


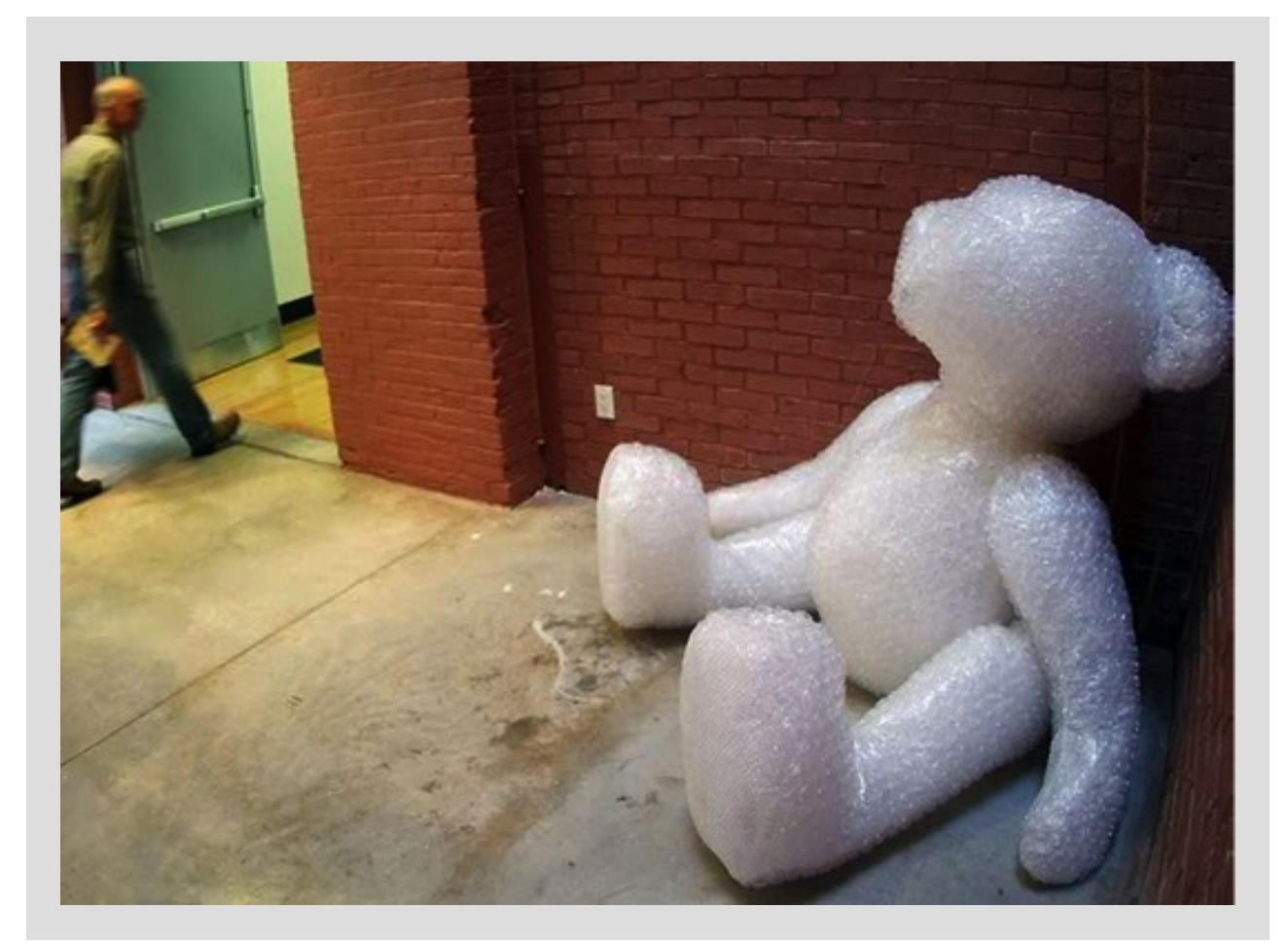

Figura 01

The Bear - Cui Xiuwen - Asian Contemporary Art Fair, Nova York, 2007

Olhando para esta imagem, faço a seguinte pergunta: seria uma imagem de arte, de publicidade, de informação, de ficção e/ou de entretenimento? Como responder a esta pergunta?

A imagem do trabalho do artista Cui Xiuwen (Figura 1), apresentado na Asian Contemporary Art Fair de Nova York, (ACAF - NY, 2007), é uma expressão eloquente dessa hibridização do mercado global de arte. Apenas dois elementos nos ajudam a situar, a caracterizar e definir a imagem desse trabalho como sendo arte. Primeiro, o espaço onde foi exposto, ou seja, uma das galerias que abrigou a referida feira; segundo, a identificação do autor como um artista chinês.

Na ausência dessas informações, professores e alunos poderiam identificá-la como uma imagem de publicidade, de informação, de entretenimento e até mesmo uma combinação de várias possibilidades. Como explica Martins (2010), os

... objetos são separados uns dos outros e classificados, ganhando valor simbólico a partir da posição que ocupam numa escala de hierarquia ou prestígio cultural e podem até mesmo ser mais valiosos quando utilizados em contextos ou funções diferentes daqueles para as quais foram inicialmente criados. (p.1) 
Até a primeira metade do século $\mathrm{XX}$, essa escala de hierarquia ou prestígio cultural sinalizava, mesmo que de forma precária e conflituosa, diferenças entre "arte", "arte popular" e "artesanato", ou, entre imagens de "arte", imagens de "publicidade" e imagens de "informação". Todavia, a partir da segunda metade do século XX essas distinções tornaram-se cada vez mais embaçadas, nebulosas, confundindo não apenas a pretensão, mas, também, a maneira de definir e delimitar esses conteúdos imagéticos e suas respectivas classificações hierárquicas. A figura/imagem do urso - que nesse caso não é de pelúcia, mas, de plástico bolha - apesar do tamanho pouco comum e de estar exposta numa feira de arte, pode ser facilmente associada a um brinquedo infantil, à publicidade de um produto a ser consumido por crianças, ou, ainda, a uma imagem de informação veiculada num noticiário como mais uma curiosidade a ser registrada no Livro Guinness dos Recordes. Mas, na matéria publicada na revista Avenue Magazine (2007), o crítico de arte Joy Y. Wang afirma que um dos "maiores desafios [da feira] é promover uma profunda compreensão da arte contemporânea asiática e suas várias formas" (p. 124).

$\mathrm{Na}$ expectativa de fomentar o interesse e discussão sobre arte contemporânea, paralelamente à feira foram organizados seminários, conferências e palestras para discutir o tema em questão com a participação dos artistas. Parte significativa das discussões gravitou em torno da questão sobre quais os limites que definem a arte contemporânea e, neste caso específico, a asiática. Ainda pensando nessa hibridização, observemos por alguns instantes, mais uma imagem. (Figura 2)

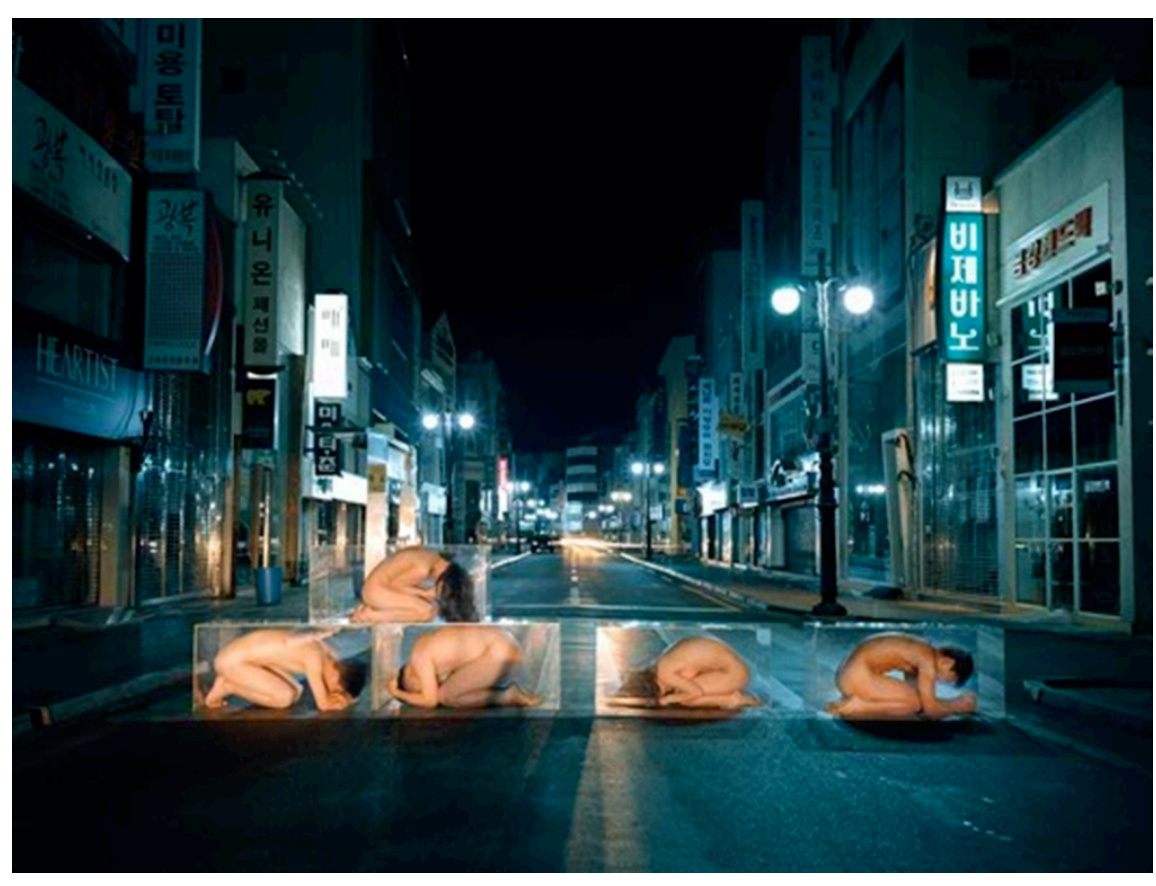




\section{Figura 02}

Atta Kim - The Museum Project No. 0001, da Série Fields, 1995

Asian Contemporary Art Fair de Nova York, 2007

Atta Kim, autor da obra da figura 2 - The Museum Project No. 0001, da Série Fields, 1995 - num dos seminários que participou, corroborou os comentários do crítico de arte Joy Y. Wang ao explicar que sua motivação ao participar da Feira era, de fato, "desafiar a audiência fazendo as pessoas refletirem sobre o que define a arte [contemporânea] asiática" (idem, p. 125).

A ideia de desafiar, provocar o público ou audiência, é uma força motriz nesses circuitos de produção simbólica, é uma maneira de chamar, convocar os indivíduos ao diálogo e a reflexão. Nesse sentido, é importante enfatizar que hoje, a cultura dos alunos, assim como a dos professores, está inoculada pela influência e desejo de produtos, objetos e imagens da cultura contemporânea. Concebidos por artistas, pelas indústrias da criatividade e pela mídia, esses artefatos são disseminados através de agressivas campanhas publicitárias e de marketing que, de maneira deliberada e com poderosa precisão, elegem crianças, jovens e adultos como alvo. Estigmatizada pela escassez de recursos e pelas práticas convencionais que a denota, como poderia a arte/educação participar dessa disputa?

Nossas escolhas falam do mundo em que vivemos, mesmo quando as pessoas vivem em sociedades/comunidades pobres e em condições econômicas precárias. Por esta razão, as campanhas institucionais/publicitárias têm como foco a imagem de artefatos/produtos e objetos artísticos a serem consumidos porque marcas, logos e grifes funcionam como atalhos mentais que nos persuadem a escolher aquelas que, por alguma razão, transmitem confiabilidade, credibilidade. A potência desse processo de persuasão fica demonstrada ao compararmos as duas imagens que seguem. (Figuras 3 e 4 ) 


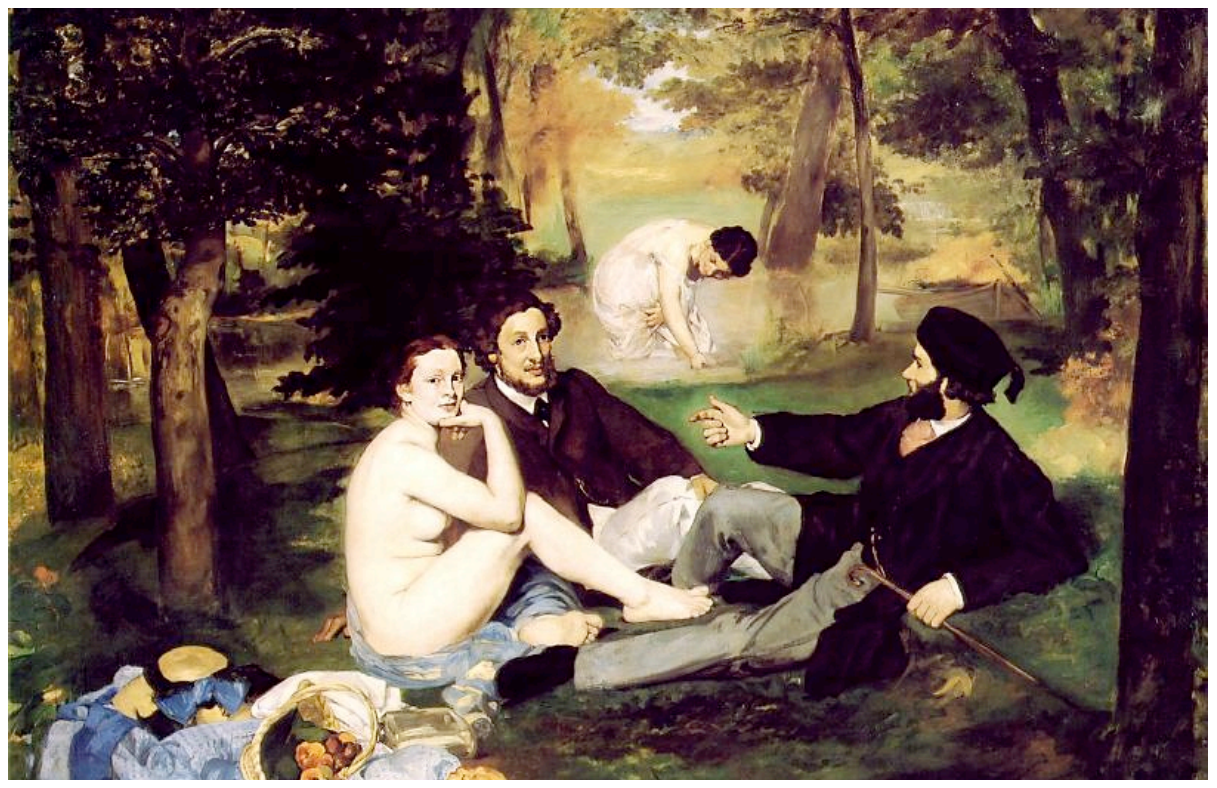

Figura 03

Edouard Manet - Le déjeuner sur I'herbe, 1863.

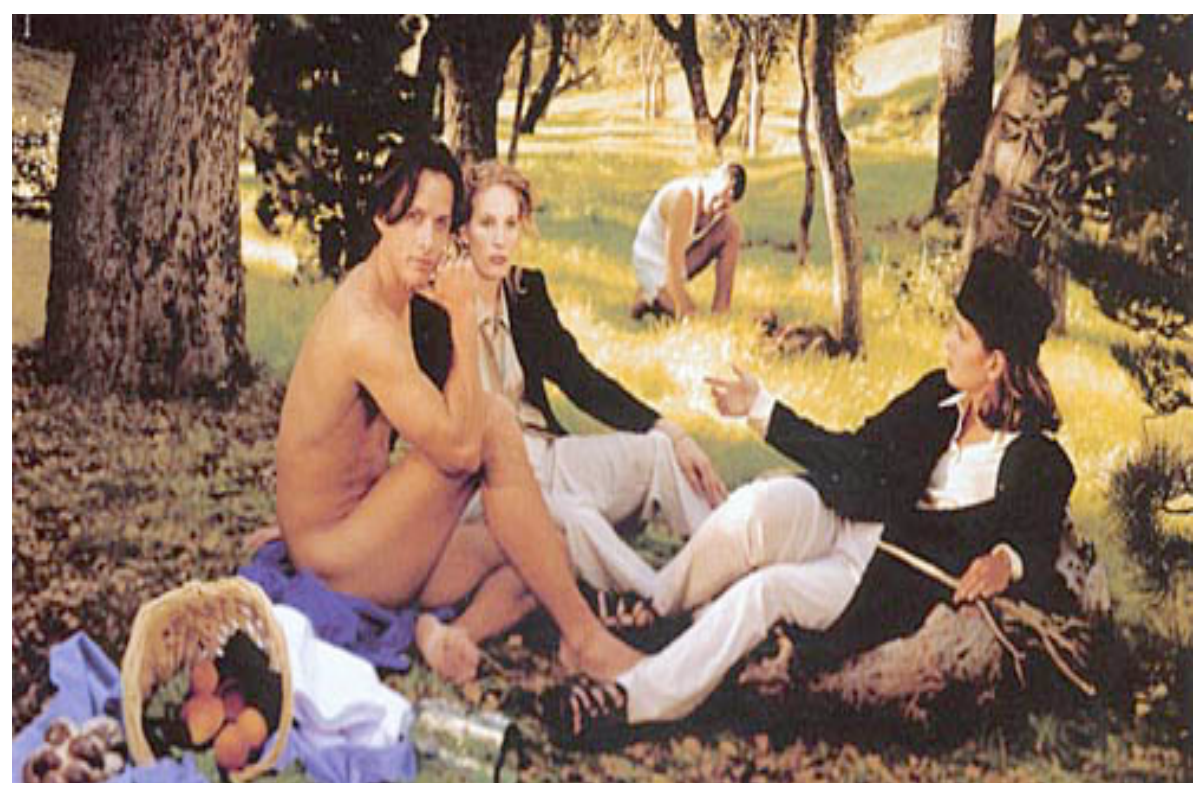

Figura 04

Campanha publicitária desenvolvida pela Hasan \& Partners Oy - Helsinke.

Esse processo de assédio e de persuasão depende da classe social das pessoas e essas escolhas estão ligadas a informação e recursos, mas, vale ressaltar que elas operam através da idealização e da expectativa dos indivíduos que querem se ver refletidos nos objetos/produtos/imagens. Os sistemas simbólicos resultam de mecanismos por meio dos quais imagem e objeto adquirem, ou lhes é atribuído, um determinado valor em relação a uma rede de significados de outras imagens e 
objetos. Eles são estabelecidos e passam a ser preservados pela tradição, sendo cultivados por meio de práticas culturais. Gradativamente, passam a ser incorporados por outros grupos e comunidades. Portanto, os sistemas simbólicos se constituem como marca e prática desejável que definem e caracterizam um grupo, comunidade ou sociedade num tempo e lugar específicos. Objetos, imagens e artefatos visuais ganham e ocupam espaços privilegiados a partir de trocas, agregação de significados e valores que os sistemas simbólicos Ihes conferem.

\section{Circunstanciando atitudes e abordagens...}

A cultura visual não estuda apenas um setor, uma parcela ou recorte desse mundo simbólico denominado "arte", mas, se preocupa com as possibilidades de percepção que se irradiam através de imagens de arte, de informação, de publicidade, de ficção e de entretenimento, traspassando o mundo simbólico em muitas direções. Deslocando-se através do espaço, como artefatos prenhes de sentidos e significados, objetos e imagens se oferecem para conexões rizomáticas potencialmente abertas para uma diversidade de interpretações e aprendizagens.

Esta atitude metodológica nos ajuda a compreender porque "as ciências humanas [e as artes] são incorretamente vistas ou tratadas como sendo metodologicamente diferentes das ciências da natureza em vez de essencialmente diferenciadas" (LANIGAN, 1979, p. 5). Como salientei anteriormente, aquilo que é conhecido é sempre parcial, é apenas parte de uma totalidade e, portanto, é necessário levar em conta a parte desconhecida para que possamos construir, mesmo que temporariamente, uma noção ou ideia de totalidade que possibilite a pesquisa.

Por esta razão a consciência do que é desconhecido torna-se importante quando fazemos pesquisa, quando analisamos e interpretamos imagens e artefatos visuais. A pesquisa ganha importância porque deve ser vista como um procedimento, instrumento através do qual podemos criar um trânsito entre consciência - uma percepção implícita (noção, ideia, suposição) - e experiência, ou seja, a explicitação da percepção. Colocando de maneira inversa, a pesquisa pode criar um fluxo entre experiência, uma percepção explícita, e consciência ou compreensão, isto é, uma percepção implícita. Esta compreensão ou atitude nos coloca em confronto com situações complexas que podem ser sintetizadas através de algumas perguntas:

- Como pesquisar, analisar e representar experiências de outras pessoas e outras culturas? 
- Como interpretar as novas territorializações do campo visual que se manifestam de maneira sutil interferindo nas concepções de espaço, tempo e lugar? Ou, ainda,

- Como educar indivíduos para territorializações do campo visual que criam modos de ver insidiosos e produzem novas formas de sociabilidade que repercutem de modo surpreendente sobre a subjetividade dos indivíduos?

A resposta a essas perguntas pode ser simples e clara, mas, exige flexibilidade e compreensão crítica para realizar deslocamentos teóricos e epistemológicos, ou seja, para deslocar o "Eu" do pesquisador como sujeito, autoridade e incluir o "Outro", não apenas como objeto ou informante da pesquisa, mas, principalmente, como copartícipe, como colaborador que tem parte ativa em avaliações, como coautor de narrativas visuais e textuais. Versiani (2005), ao discutir a relação "Eu" - "Outro" na pesquisa, detalha este posicionamento explicando que

... ao destituir-se do poder de falar sobre os outros, ou pelos outros, pesquisadores (...) deveriam articular-se para desempenhar outro papel, o de falar com os outros, viabilizando a circulação de discursos de outros sujeitos complexos e singulares - e de seus respectivos saberes, emprestando-Ihes o poder de circulação de comunicados, poder que possuem exatamente por ocupar um lugar em instituições de saber. (p. 67)

Nesse cenário de crise e conflito conceitual, nas últimas duas décadas surgiram distintas compreensões de pesquisa que tem experimentado crescimento e diversificação significativos ganhando credibilidade e se consolidando em diferentes áreas de conhecimento, mas, especialmente, nas ciências humanas e nas artes.

Aumenta a cada dia o número de estudiosos, pesquisadores e profissionais preocupados em pensar uma "reconfiguração da representação e apresentação etnográfica como um modo de reconceituar o papel das mídias visuais e audiovisuais..." (GONÇALVES e HEAD, 2009, p. 9), ou seja, como incorporar essas mídias e artefatos ao corpus de conhecimento da arte/educação, como "estender as fronteiras deste corpo disciplinar através das mídias visuais, tanto como meio quanto como tema de análise" (Ibid.). O que se busca é colocar em perspectiva a problemática dessas conexões, principalmente, como abordar, investigar e tentar compreender o modo como os indivíduos concebem e constroem o mundo ao seu redor, o imaginário imagético que essas mídias animam, como atribuem sentido ao que estão fazendo, como interagem com esses fenômenos, processos, situações e artefatos sociais. Uma dessas abordagens é a educação da cultura visual. 


\section{Circunstanciando atitudes e princípios...}

A necessidade e a velocidade de consumir dos indivíduos parece permanecer porque existem produtos, artefatos, ideias e imagens para todos os bolsos. Ao mesmo tempo, isso nos leva a constatação de que a territorialização do campo visual tem diferentes implicações para diferentes indivíduos, explicitando e definindo não apenas o modo como vemos ou somos vistos, mas, também, e principalmente, como e o que somos capazes de ver. As implicações dessa abordagem de pesquisa têm gerado mudanças ao se configurarem como "posições e trilhas fecundando nossas escolhas de temas, perspectivas epistemológicas e analíticas, processos que são colaborativos e não apenas autorais" (MARTINS e TOURINHO, 2013, p. 13). Podemos apontar algumas dessas mudanças como:

- a pluralização de teorias da arte e da imagem;

- a crescente inclusão, em contextos acadêmicos e de produção, de reflexões alternativas às teorias e práticas tradicionais, passando a levar em conta reflexões sendo produzidas por pessoas ligadas a grupos minoritários;

- o crescente distanciamento do pensamento excludente e hierarquizante orientado para a construção de alternativas conceituais que buscam outras formas para explicar os fenômenos contemporâneos;

- a substituição de parâmetros/referências dicotômicos por parâmetros de multiplicidade;

- a ênfase na relação receptor/audiência como produtora de significados.

Esses conceitos e ideias que pouco a pouco ganharam espaço nas instituições e hoje estão se tornando correntes no campo das artes e das humanidades, são consequência dos debates e da consolidação gradativa de diferentes praticas críticas e pós-críticas oriundas do pós-estruturalismo, pós-colonialismo, feminismo, estudos queer e outras que ficaram conhecidas e foram decisivas nas guerras culturais que envolveram as humanidades na década de 80 do século passado com o objetivo de oferecer resistência às circunstâncias e situações de hegemonia cultural.

Os exemplos que foram apresentados são representativos das mudanças e transformações que estão acontecendo na área cultural e, consequentemente, tornaram-se centrais nas discussões, estudos e debates sobre a pós-modernidade. Embora esses avanços epistemológicos e teóricos sejam significativos, algumas questões resistem e merecem a nossa atenção: Essas práticas estão sendo 
estudadas e discutidas? Estão presentes nos nossos currículos? Estão presentes nas nossas concepções, na nossa prática de pesquisa?

Essas experiências, processos e práticas, por vezes considerados secundários ou periféricos, com frequência são identificados como iniciativas de grupos minoritários, excludentes ou, ainda, desestabilizadores de uma ordem acadêmica e institucional estabelecida. No entanto, vale lembrar que instabilidade, ruídos e deslocamentos devem ser vistos como oportunidade para receber/agregar diferentes ideias, outras vozes, manifestações e práticas que podem ser vitalizantes para o ambiente da academia.

É necessário aprender a lidar com os desafios de uma abordagem metodológica multilógica que se propõe a trabalhar com a multiplicidade, a complexidade e a diversidade. Os sentidos e os significados têm uma natureza persistentemente múltipla. Nossas observações sobre o mundo são moldadas por preconceitos, prejulgamentos e marcas que desconhecemos. Como pesquisadores, devemos entender a existência dessas dinâmicas e sermos humildes ao fazer afirmações sobre suas interpretações. O mundo complexo comporta diversas explicações que coexistem em uma tensão produtiva. A imagem da figura 5 é um exemplo que pode nos ajudar a compreender que o mundo é complexo e, portanto, comporta diversas explicações que coexistem em uma tensão produtiva.

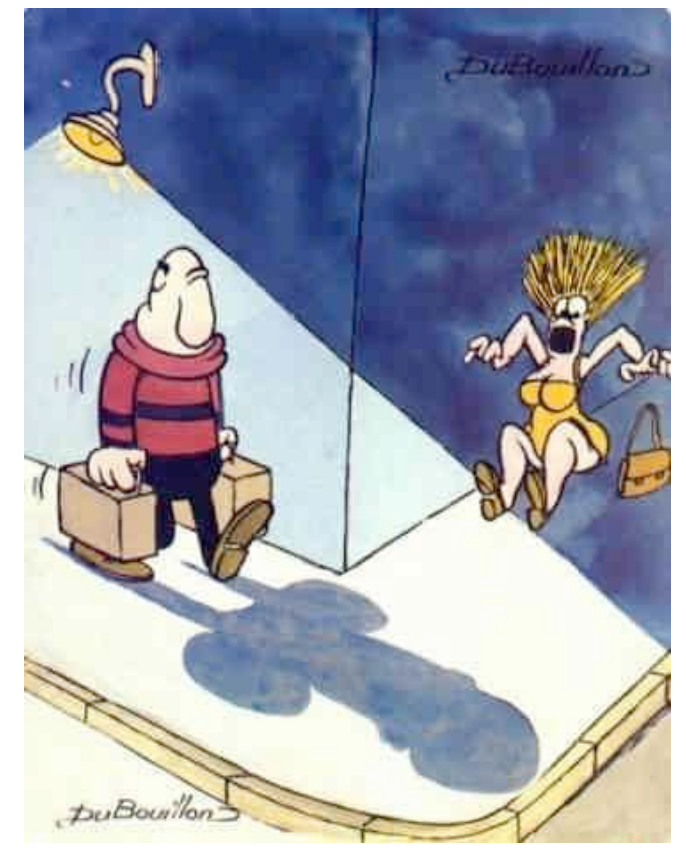

Figura 05 


\section{Concluindo...}

Pesquisadores que adotam esta perspectiva incorporam/utilizam formas de indagação visual, performativa, poética, musical e narrativa nas suas investigações. Essas abordagens, além de estender as fronteiras das concepções e práticas de investigação vigentes, possibilitam explorar/experimentar outras maneiras de fazer pesquisa. Ao mesmo tempo, estas abordagens de pesquisa têm em comum uma discussão sobre os conteúdos da investigação, sua interpretação (explicação dos conteúdos) e a função do colaborador, fortalecendo a relação entre pesquisador e colaborador/participante que se intensifica tornando-se mais igualitária.

Existir é, antes de tudo, fazer-se presente e ser reconhecido numa instância pública e simbólica que tem como pressuposto a interação entre arte, imagem, narrativa e ação (ARENDT, 2005). É partilhar e compartilhar artefatos artísticos, imagens e visualidades como práticas sociais e culturais que se estabelecem e se desestabilizam na teia de relações e significações humanas onde cada indivíduo se insere e participa a seu modo. Por esta razão fazemos arte, estudamos, ensinamos e pesquisamos arte, para nos sentir vivos, para nos sentir humanos.

\section{Referências}

ARENDT, Hannah. A condição humana. Rio de Janeiro: Forense Universitária, 2005.

CAMPOS, Ricardo. Introduçao à Cultura Visual - Abordagens e Metodologias em ciências Sociais. Lisboa: Editora Mundos Sociais, 2013.

GONÇALVES, Marco Antonio e HEAD, Scott (Orgs.). Devires Imagéticos - a etnografia, o autor e suas imagens. Rio de Janeiro: FAPERJ/7Letras, 2009.

HALL, Stuart (Org.). Representation. Cultural Representations and Signifying Practices. Londres: Sage Publications, 1997.

ILLERIS, Helene e ARVEDSEN, Karsten, Fenômenos e Eventos Visuais: algumas reflexões sobre currículo e pedagogia da cultura visual. In: MARTINS, Raimundo e TOURINHO, Irene (Orgs.), Culturas das Imagens - Desafios para a arte e para a educação. Santa Maria: Editora da UFSM, 2012, p. 283-309.

LANIGAN, R. The Phenomenology of Human Communication. Philosophy Today. Celina: Ohio, Messenger Press, $N^{\circ} 23,1979$.

MARTINS, R. Pensando com Imagens - Para compreender criticamente a experiência visual. In: RODRIGUES, E. T. e LIMA, H. A. (Orgs.) Educação das artes visuais na perspectiva da cultura visual: conceituações, problematizações e experiências. Goiânia: Secretaria da Educação do Estado de Goiás, 2010. 
MIRZOEFF, Nicholas. An Introduction to Visual Culture. Londres: Routledge, 1999.

MITCHELL, W. J. T. Showing seeing: a critique of visual culture. Journal of Visual Culture, I (2), p. 165-181, 2002.

PINNEY, Christopher. Four types of visual culture. Em TILLEY, C.; KUERCHLERFOGDEN, S.; ROWLANDS, M. (Orgs.), Handbook of Material Culture. Londres: Sage Publications, 2006, p. 131-144.

ROSE, Gillian. Visual Methodologies: An Introduction to the Interpretation of Visual Materials. London: Sage, 2011.

TOURINHO, I. e MARTINS, R. Imagens como conhecimento e investigação. In: MARTINS, R. e TOURINho, I (Orgs.), Processos \& Práticas de Pesquisa em Cultura Visual \& Educação. Santa Maria: Editora da UFSM, 2013, p.13-17.

VERSIANI, Daniela Beccaccia. Autoetnografias: conceitos alternativos em construção. Rio de Janeiro: 7 Letras, 2005.

WALKER, John e CHAPLIN, Sarah. Visual Culture - An Introduction. Manchester: Manchester University Press, 1997.

WANG, J. Y. Avenue Magazine. New York: October 2007, p. 123-126.

\footnotetext{
Raimundo Martins é doutor em Educação/Artes pela Universidade de Southern Illinois (EUA), pós-doutor pela Universidade de Londres (Inglaterra) e pela Universidade de Barcelona (Espanha), onde também foi professor visitante. É professor titular e diretor da Faculdade de Artes Visuais, docente permanente do Programa de Pós Graduação em Arte e Cultura Visual - mestrado e doutorado da Universidade Federal de Goiás e editor da Coleção Desenredos. martins.raimar@gmail.com
}

Recebido em 23/09/2014

Aprovado em 15/12/2014 